\title{
Dislocation Density Reduction During Impurity Gettering in Multicrystalline Silicon
}

\author{
H. J. Choi, M. I. Bertoni, J. Hofstetter, D. P. Fenning, D. M. Powell, S. Castellanos, and T. Buonassisi
}

\begin{abstract}
Isothermal annealing above $1250{ }^{\circ} \mathrm{C}$ has been reported to reduce the dislocation density in multicrystalline silicon (mc-Si), presumably by pairwise dislocation annihilation. However, this high-temperature process may also cause significant impurity contamination, canceling out the positive effect of dislocation density reduction on cell performance. Here, efforts are made to annihilate dislocations in mc-Si in temperatures as low as $820^{\circ} \mathrm{C}$, with the assistance of an additional driving force to stimulate dislocation motion. A reduction of more than $60 \%$ in dislocation density is observed for mc-Si containing intermediate concentrations of certain metallic species after $P$ gettering at $820^{\circ} \mathrm{C}$. While the precise mechanism remains in discussion, available evidence suggests that the net unidirectional flux of impurities in the presence of a gettering layer may cause dislocation motion, leading to dislocation density reduction. Analysis of minority carrier lifetime as a function of dislocation density suggests that lifetime improvements after $\mathbf{P}$ diffusion in these samples can be attributed to the combined effects of dislocation density reduction and impurity concentration reduction. These findings suggest there may be mechanisms to reduce dislocation densities at standard solar cell processing temperatures.
\end{abstract}

Index Terms-Al gettering, dislocation density, dislocation impurity interaction, multicrystalline silicon, $\mathbf{P}$ gettering.

\section{INTRODUCTION}

M ULTICRYSTALLINE silicon (mc-Si) currently constitutes nearly $50 \%$ of the worldwide solar cell production [1]. The significant market share of mc-Si originates from its low cost and established manufacturing process. However, lower efficiencies of mc-Si solar cells compared with singlecrystalline silicon solar cells, mainly due to much larger concentrations of crystal defects and impurities, partially offset the economic benefits of the lower cost material [2]-[4]. During

Manuscript received June 3, 2012; revised July 30, 2012; accepted August 17, 2012. Date of publication October 15, 2012; date of current version December 19, 2012. This work was supported in part by the U.S. Department of Energy under Contract DE-EE0005314 and a Technological Innovation Grant from the Deshpande Center, as well as by the Engineering Research Center Program of the National Science Foundation and the Office of Energy Efficiency and Renewable Energy of the U.S. Department of Energy under National Science Foundation Cooperative Agreement EEC-1041895. The work of J. Hofstetter was supported by an Alexander von Humboldt foundation Fellowship. The work of D. P. Fenning was supported by an National Science Foundation Graduate Research Fellowship. The work of S. Castellanos was supported by the Roberto Rocca Foundation. The work of D. M. Powell was supported by the Department of Defense through the National Defense Science and Engineering Graduate Fellowship program.

The authors are with Massachusetts Institute of Technology, Cambridge, MA02139 USA (e-mail: hyunjoo@mit.edu; mbertoni@mit.edu; jhofstet@ mit.edu; dpfenning@gmail.com; dmpowell@mit.edu; sergioc@mit.edu; buonassisi@mit.edu).

Color versions of one or more of the figures in this paper are available online at http://ieeexplore.iee.org.

Digital Object Identifier 10.1109/JPHOTOV.2012.2219851
Si solar cell processing, two main processes are used to reduce the impact of defects and improve the performance of mc-Si materials: 1) gettering of fast-diffusing metal impurities during $\mathrm{P}$ diffusion and Al back contact formation, based on an enhanced metal solubility in the P-diffused layer and liquid Al-Si layer [5], [6], and 2) passivation of crystal defects with atomic hydrogen that diffuses from a $\mathrm{SiN}_{x}: \mathrm{H}$ coating layer into silicon bulk during contact cofiring [7].

Metal impurities such as iron, nickel, and copper are present in silicon feedstock material, and are often further introduced during ingot growth and solar-cell processing [8]. These metallic species, with high diffusivity in $\mathrm{Si}$ [9], can be gettered from grains with low-dislocation densities and, consequently, the minority carrier lifetime in these regions increases [10]. In regions with high dislocation densities $\left(>10^{6} \mathrm{~cm}^{-2}\right)$, however, the gettering process has been found to be minimally effective [11]. Dissolved metal point defects or metal-silicide precipitates may segregate to the dislocation strain field and/or bind to the dislocation core, creating additional energy barriers to gettering [12]. These impurities form deep-level recombination centers that deteriorate solar-cell performance [13], [14].

Atomic hydrogen in-diffusion from a $\mathrm{SiN}_{x}: \mathrm{H}$ coating layer during contact firing has been reported to show less effective lifetime improvement as dislocation density increases [15]. Hence, the lifetime improvement of mc-Si during solar cell processing is strongly limited in the presence of high-dislocation densities. Alternative approaches to remove dislocations are required, in addition to gettering or passivation methods.

Certain high-temperature thermal annealing processes have been reported to effectively reduce the density of dislocations in $\mathrm{mc}-\mathrm{Si}$ [16]-[19]. It is observed that annealing above $\sim 1000^{\circ} \mathrm{C}$ in the presence of an appropriate driving force (e.g., interaction between dislocations, image forces, or applied external mechanical load) can result in dislocation density reduction, perhaps via pairwise dislocation annihilation [20] and/or accumulation at sinks including surfaces and grain boundaries.

The underlying physics enabling these observations concern the dislocation mobility. In pristine samples, dislocation velocity $v$ is given as [21]

$$
v=v_{\mathrm{o}} \tau \exp \left(\frac{-Q}{k_{\mathrm{B}} T}\right)
$$

where $T$ is the absolute temperature, $\tau$ is the shear stress, and $Q$ is the activation energy. Dislocations become mobile within certain crystallographic glide planes at temperatures above the brittle-to-ductile transition temperature (i.e., $530-660^{\circ} \mathrm{C}$ for $\mathrm{Si}$, depending on dopant concentration and strain rate) [22]. Vacancy diffusion promotes edge dislocation climb out of the glide 
TABLE I

DESCRIPTION OF SAMPLE PREPARATION AND EXPERIMENTAL PROCEDURE

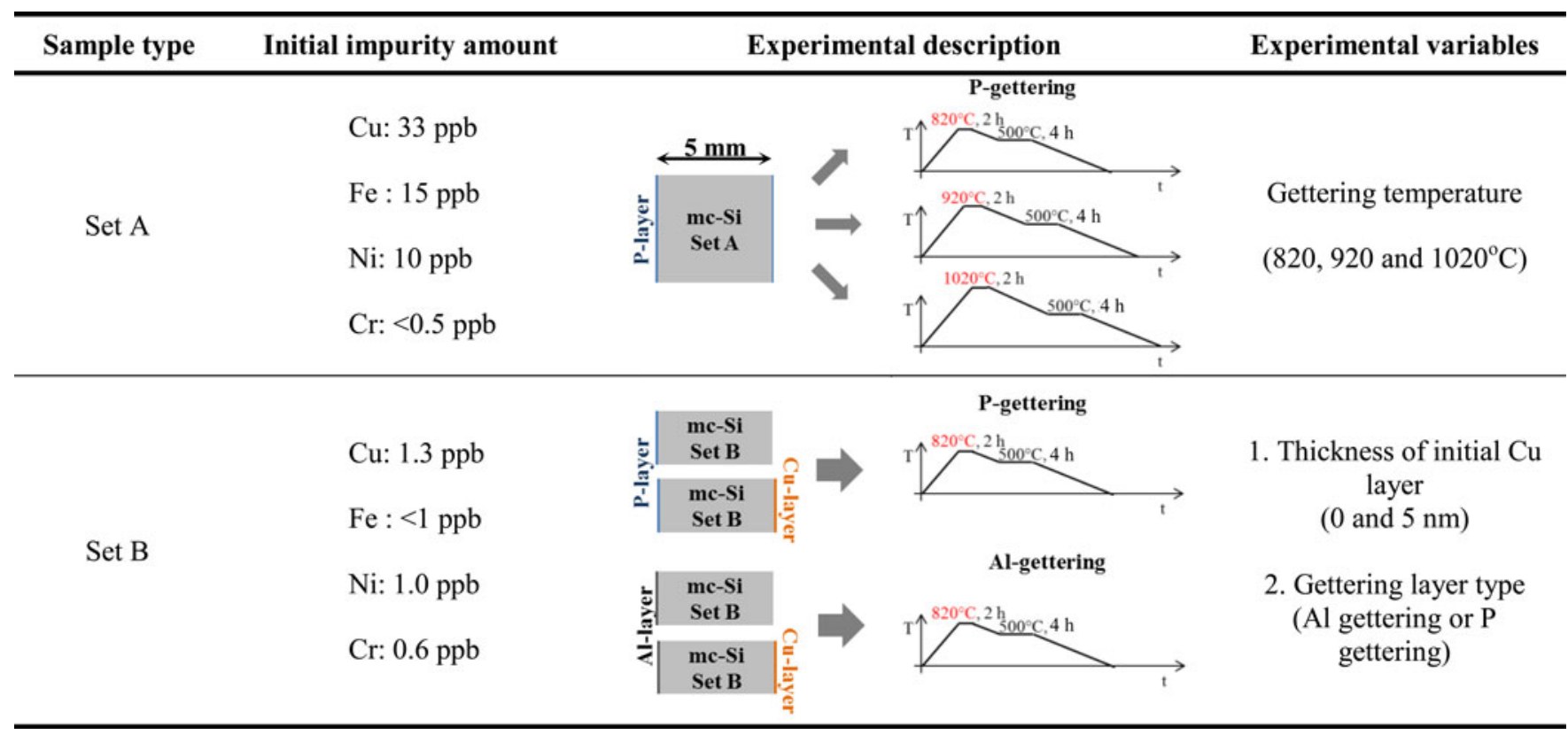

plane, further enhancing dislocation mobility at temperatures above $\sim 1000^{\circ} \mathrm{C}[23]$. The role of stress is more subtle; stress is observed to enhance dislocation motion but can also contribute to dislocation multiplication [24].

The high temperatures required by these processes can also cause impurity contamination, offsetting the minority carrier lifetime benefits of reduced dislocation densities [17], [18]. Thus, achieving comparable levels of dislocation-density reduction at lower temperatures is highly desirable to minimize the impact of external contamination. To offset the exponential temperature dependence of dislocation velocity, a strong driving force for dislocation motion is needed.

Here, we report a dislocation density reduction at temperatures as low as $820^{\circ} \mathrm{C}$ in the presence of a gettering layer and in samples containing moderate concentrations of certain metallic species. Our prevailing hypothesis is that impurity flux to the gettering layer drives dislocation motion and density reduction; control experiments suggest that vacancy injection by the gettering layer is insufficient to produce this effect. Two separate experiments were conducted to examine the effect of gettering temperature and the amount of impurities. Finally, the effect of dislocation density reduction on minority carrier lifetime is investigated, and the influences of impurity gettering and dislocation-density reduction are decoupled using an analysis inspired by the Donolato model [25].

\section{EXPERIMENTAL DETAILS}

The dislocation density before and after an external gettering process was examined in mc-Si samples (5-mm-thick in the growth direction and $3.5 \times 1.8 \mathrm{~cm}^{2}$ in area) prepared from two bricks of different impurity contamination levels (coming from different suppliers): Samples from a brick with high as-grown impurity concentration were designated set A, while samples from a brick with comparably low contamination were desig- nated set B. As-grown impurity concentrations were measured by inductively coupled plasma mass spectrometry (ICP-MS, Perkin-Elmer Sciex Elan 6000, Norwalk, CT). It confirms that samples from set A have moderate contamination levels (33-ppbw $\mathrm{Cu}, 15$-ppbw $\mathrm{Fe}, 10-p p b w \mathrm{Ni}$, and 0.5-ppbw $\mathrm{Cr}$ ), while samples from set B have low contamination levels (less than 1.5 ppbw of all analyzed elements), as shown in Table I. This difference may originate from the use of different feedstock materials or different crystal growth environments.

Samples were cut $\sim 10 \mathrm{~cm}$ away from the top of the as-grown mc-Si bricks, to avoid very high-contamination levels typically found at the ingot borders. A sister control sample for each experimental sample was cut from the ingot material directly adjacent in the growth direction. Samples were polished using $\mathrm{SiC}$ paper (1200 grit) and polishing cloths with diamond paste (to 3- $\mu$ m particle size). Then, samples were cleaned with a standard RCA process, followed by a HF dip [26]. The repeatability of the experiment was investigated by repeating the same experiment more than three times with different samples. However, the data used in the present manuscript were obtained from one sample to ensure a high degree of comparability.

The first experiment investigated the effect of the gettering temperature, using silicon with moderate impurity contents (set A). A layer of P dopant in an ethanol solution was deposited over the entire sample surface on both sides of samples to create an "infinite" P source. As-deposited samples were loaded into a mullite tube in a furnace at room temperature, heated up to the target temperatures (i.e., 820, 920, and $1020^{\circ} \mathrm{C}$ ) at $6.5^{\circ} \mathrm{C} / \mathrm{min}$, annealed for $2 \mathrm{~h}$ in air, cooled down to $500^{\circ} \mathrm{C}$ at $3{ }^{\circ} \mathrm{C} / \mathrm{min}$, held at $500^{\circ} \mathrm{C}$ for $4 \mathrm{~h}$ for further gettering, and then unloaded. The $500^{\circ} \mathrm{C}$ plateau is introduced with the explicit purpose of reducing the bulk concentration of dissolved metallic impurities, either by relaxation $(\mathrm{Al})$ or combined relaxation/segregation $(\mathrm{P})$, inspired by impurity time-temperaturetransformation diagrams [27], [28]. Note that $500{ }^{\circ} \mathrm{C}$ is below 
Set A (mc-Si with moderate impurity content)

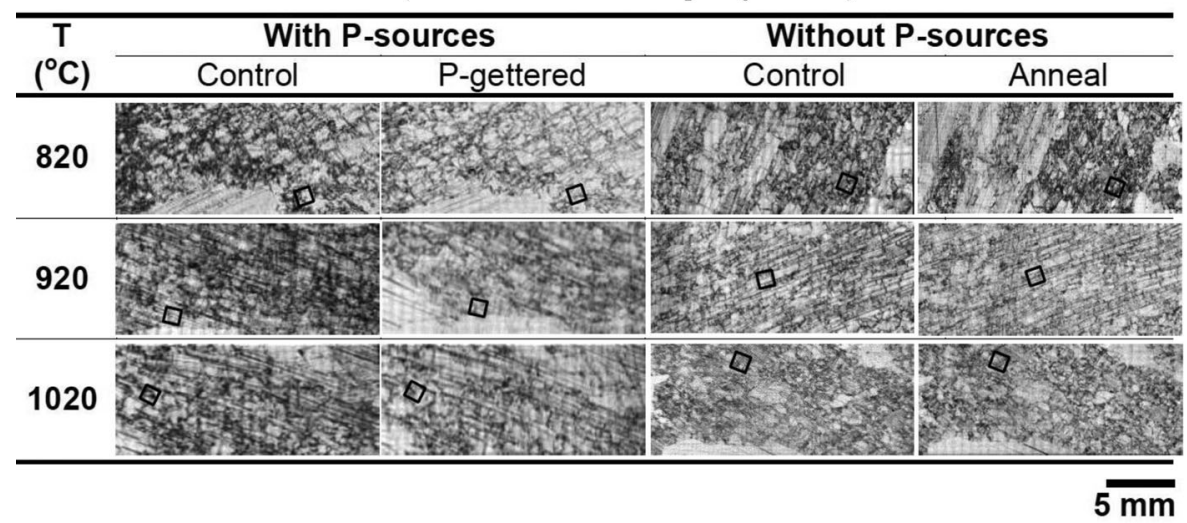

Fig. 1. Flatbed scanner images of dislocation-etched samples from set A; control sister (as-grown) and annealed samples grouped into three different annealing temperatures (i.e., 820,920 , and $1020^{\circ} \mathrm{C}$ ) and two different surface treatments (with and without a P layer). High-resolution optical microscope images of representative black squares are shown in Fig. 2.

the Si brittle-to-ductile transition temperature [22] and the Al-Si eutectic temperature.

The second experiment was designed to investigate the effect of impurity solute atom flux during gettering, using silicon with low-impurity contents (sample set B); half the samples were intentionally contaminated with high-purity $\mathrm{Cu}$, and the other half were gettered without intentional $\mathrm{Cu}$ contamination for comparison. A Cu film with a thickness of $5 \mathrm{~nm}$ was deposited on one side of the samples (set B) using a thermal evaporator (TE, Sharon). Samples were evaporated simultaneously to promote uniform $\mathrm{Cu}$ thickness deposition. On half of the $\mathrm{Cu}$-contaminated samples and half of the un-contaminated samples, a P dopant in an ethanol solution was deposited on the side opposite the $\mathrm{Cu}$ film. On the remaining half sample sets, a 1- $\mu \mathrm{m} \mathrm{Al} \mathrm{layer} \mathrm{was} \mathrm{deposited} \mathrm{on} \mathrm{the} \mathrm{side} \mathrm{opposite} \mathrm{to} \mathrm{the} \mathrm{Cu}$ layer, using the same TE tool. Then, all samples were annealed at $820^{\circ} \mathrm{C}$ for $2 \mathrm{~h}$ in air using the same temperature profile of the first experiment. Table I summarizes sample preparation and experimental procedure for all samples.

For all samples in both sample sets, $1 \mathrm{~mm}$ of the surface was removed by mechanical polishing after annealing to fully remove the gettering layer and to reveal bulk regions, where the effect of image forces on dislocation motion is negligible [19]. To reveal crystal defects, all samples were etched in a volumetric ratio mixture of 9:0:1 (nitric, acetic and hydrofluoric acid, respectively), then agitated in a Sopori etch (2:15:36) [29] for $30 \mathrm{~s}$, and finally quenched in 9:0:1 mixture for 1-2 s. This process leads to the formation of small dislocation etch pits, where dislocations intersect the surface of the silicon wafer.

The microstructure of the etched samples was examined using an optical microscope. A Secco etch [30] was also used for comparison, and the etch pits revealed by Secco etch (not shown here) were found to be comparable with those revealed by Sopori etch for a control sample and an experimental sample annealed at $820^{\circ} \mathrm{C}$ exhibiting strong dislocation-density reduction.

The dislocation density $\left(\mathrm{cm}^{-2}\right)$ was calculated using a MATLAB program. The program first converts the color microscope image into binary black and white and then filters out dots that are considered too small to be single dislocations. The program then categorizes surface features into two groups, single dislocations and dislocation clusters, based on area. All features with an area smaller than a preset maximum size of a single dislocation are presumed to be single dislocations. Then, the average size and total number of single dislocations are computed. The total cluster area is then divided by the average area of single dislocations to obtain an approximate count of the dislocations contained in clusters. The dislocation density is computed by adding the number of single dislocations and those contained in clusters, and then dividing by total area. The maximum dislocation density that can be detected using this program is $\sim 4 \times$ $10^{7} \mathrm{~cm}^{-2}$, depending on precise etching conditions. The algorithm of the program was partially inspired by the work of Rinio [31] and other authors. The automatic dislocation counting has been verified previously by comparison with hand counting selected areas and found to be within $20 \%$.

For sample set A, microwave photoconductive decay ( $\mu$-PCD, Semilab, WT-2000) was employed to evaluate the minority carrier lifetime before and after P gettering. Before the measurements, all samples were polished to $500 \pm 100 \mu \mathrm{m}$ in thickness and dipped in HF, and surfaces were passivated using iodine ethanol. Since the sample thickness is relatively large and the minority carrier lifetime of samples is relatively low (less than $15 \mu \mathrm{s}$, shown later), the effective lifetime does not significantly vary with sample thickness; a 20\% difference (i.e., $\sim 100 \mu \mathrm{m}$ ) in the sample thickness results in less than a $0.1 \%$ difference in the effective lifetime. For sample set B, before and after annealing, the front and back sides of each sample were analyzed using X-ray fluorescence spectroscopy (XRF, XEPOS III) to monitor changes in impurity concentrations at the surfaces.

\section{RESULTS}

Fig. 1 shows flatbed scanner images of dislocation-etched samples from mc-Si with moderate contamination levels (set A). As depicted in the table form of the figure, the samples were grouped into three different annealing temperatures (i.e., 820, 
Set A (mc-Si with moderate impurity content)

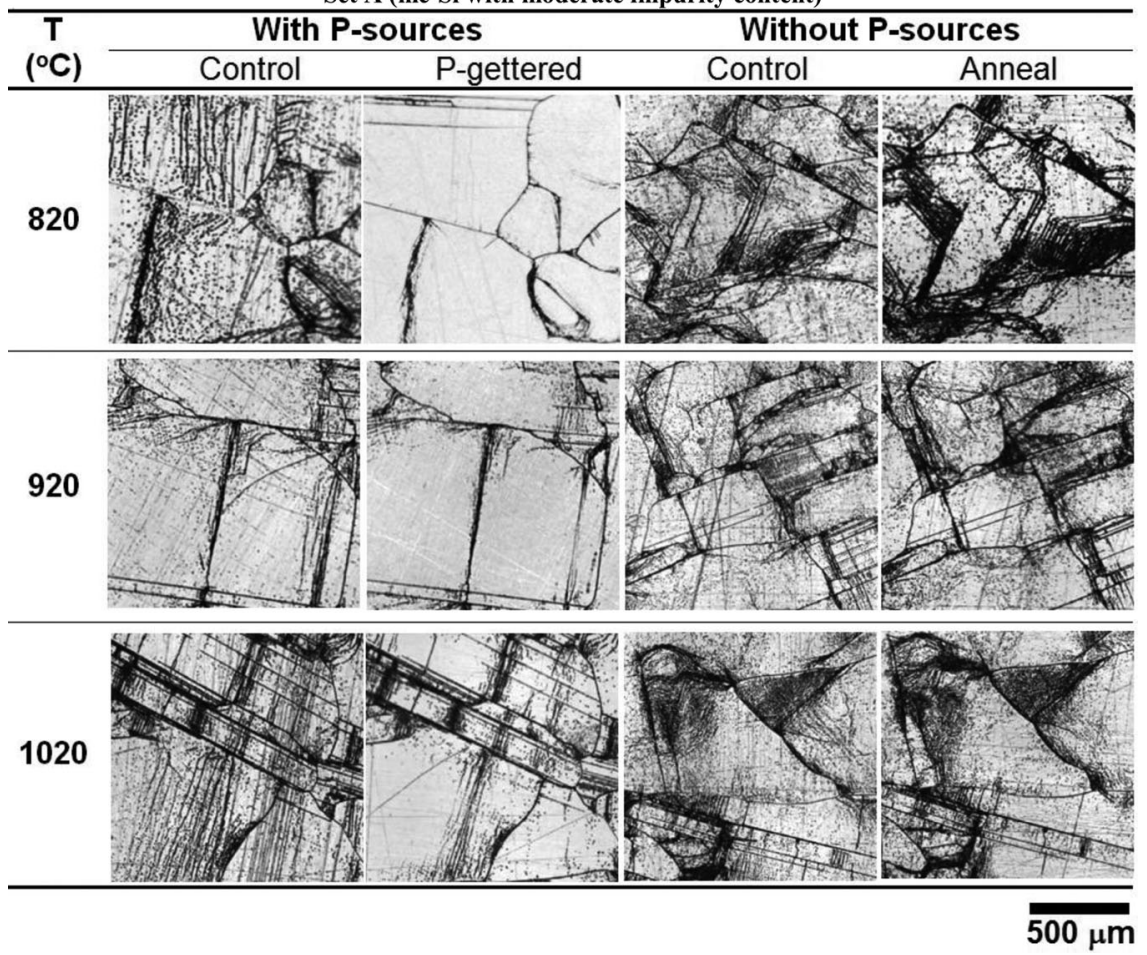

Fig. 2. Optical microscope dislocation etch pit images of control sister (as-grown) and annealed samples from set A grouped into three different annealing temperatures (i.e., 820,920 and $1020^{\circ} \mathrm{C}$ ) and two different surface treatments (with and without a P layer).

920, and $1020^{\circ} \mathrm{C}$ ) and two different surface treatments (with and without a P layer). Every sample has a control sister (asgrown) that was kept at room temperature, which is also shown in Fig. 1.

Optical microscope dislocation etch pit images of the representative areas marked by the black rectangles in Fig. 1 are shown in Fig. 2. Dislocation etch pits with sizes ranging from 0.5 to $5 \mu \mathrm{m}$ are observed in the grains, which range in size from $100 \mu \mathrm{m}$ to $2 \mathrm{~mm}$. Dislocation counting was conducted for every $1-\mathrm{mm}^{2}$ section of the whole samples. As a result, most of the dislocations $(\sim 65 \%)$ are removed after $\mathrm{P}$ gettering at $820^{\circ} \mathrm{C}$, and the number of dislocations remaining after gettering increases with gettering temperature; a dislocation density reduction of $\sim 40 \%$ and $\sim 20 \%$ is observed after P gettering at $920^{\circ} \mathrm{C}$ and $1020^{\circ} \mathrm{C}$, respectively. Without a $\mathrm{P}$ source, however, the number and distribution of dislocations are relatively constant at all processing temperatures.

To quantify and compare dislocation densities between samples, dislocation counting was conducted for every $1 \times 1 \mathrm{~mm}^{2}$ section of the control sisters (as-grown) and P-gettered samples from set A. Histograms based on the dislocation number density from this analysis are shown in Fig. 3. The dislocation density of as-grown samples is in the range from $10^{4}$ to $10^{8} \mathrm{~cm}^{-2}$, which is typical for mc-Si [32], and the largest area fraction shows dislocation densities above $10^{7} \mathrm{~cm}^{-2}$. After $\mathrm{P}$ gettering, the peak in the histogram shifts toward lower dislocation densities, meaning that the dislocation density is reduced for a significant portion of the sample for all temperatures. "Bad regions" in set A material with dislocation densities above $10^{7} \mathrm{~cm}^{-2}$ improve dramatically and are rare after P gettering.
Fig. 4 shows minority carrier lifetime maps of control sister and P-gettered samples from set $\mathrm{A}$, which were measured by $\mu$-PCD. The overall lifetime is enhanced significantly after $\mathrm{P}$ gettering, possibly due to both impurity and dislocation density reduction. In the following discussion, we aim to decouple these two effects. The lifetime is enhanced more significantly at lower temperatures, which is consistent with a stronger decrease in dislocation density at lower temperature; values increased from $\sim 0.8$ to $\sim 14.5 \mu \mathrm{s}, 1.6$ to $6.7 \mu \mathrm{s}$, and 1.9 to $6.4 \mu \mathrm{s}$ after P gettering at 820,920 , and $1020^{\circ} \mathrm{C}$, respectively.

The minority carrier lifetime was also measured for every $1 \times 1 \mathrm{~mm}^{2}$ section of control sister (as-grown) and P-gettered samples from set A, consistent with dislocation density counting, to compare the lifetime distribution before and after P gettering at three different temperatures. Histograms based on the minority carrier lifetime of each section are shown in Fig. 5. The lifetime of P-gettered samples is distributed over a wide range, and most sections show a lifetime higher than $5 \mu \mathrm{s}$, while the initial lifetime of all sections of as-grown samples is below $5 \mu \mathrm{s}$.

Our preliminary results suggest that the gettering source, presumably with the presence of a certain amount of impurities, significantly stimulates dislocation movement at temperatures as low as $820^{\circ} \mathrm{C}$. To decouple the effects of gettering source and metal impurities on dislocation movement during gettering, the second experiment was conducted using higher purity silicon (sample set $\mathrm{B}$ ). $\mathrm{Al}$ and $\mathrm{P}$ gettering were conducted for as-grown samples from set $\mathrm{B}$ with and without an additional $\mathrm{Cu}$ film on the opposite side. XRF spectra, shown in Fig. 6, demonstrate that, in the presence of an external $\mathrm{Cu}$ film, a significant amount 


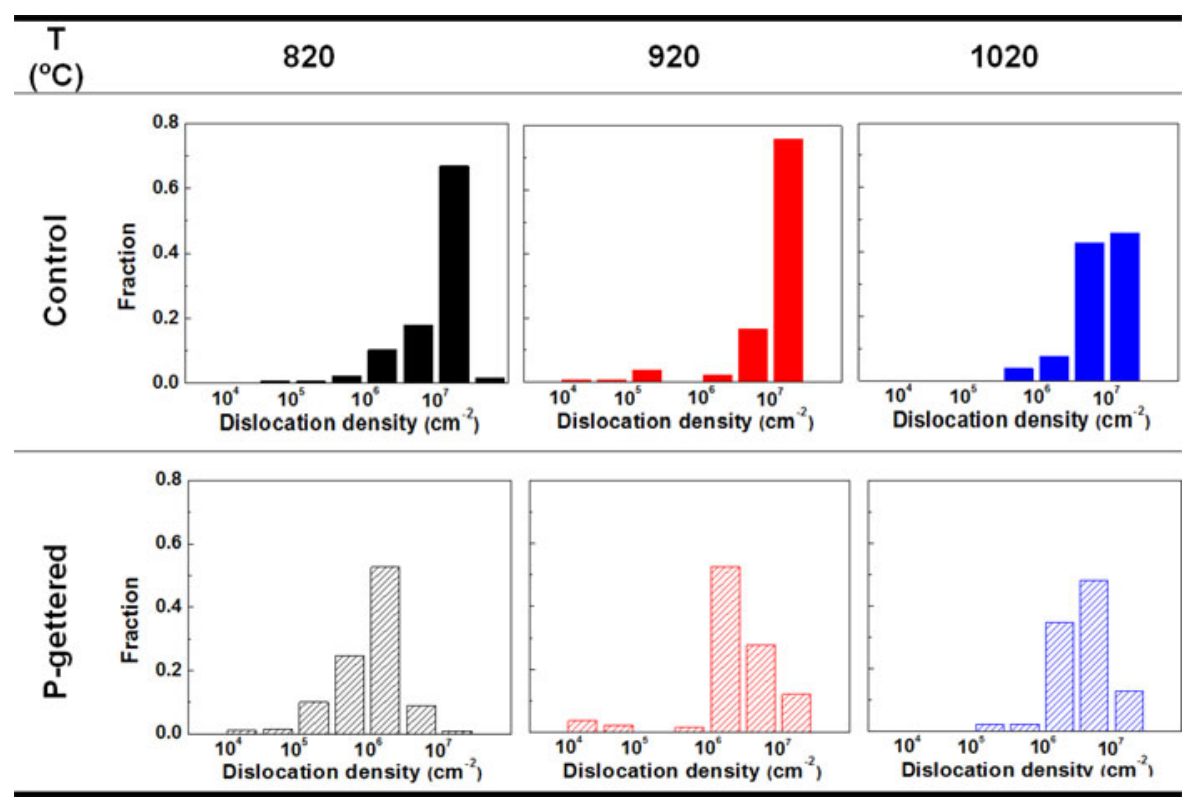

Fig. 3. Histograms of the dislocation number density distribution throughout the samples from set A, where the counting was conducted for every 1 -mm ${ }^{2}$ section of the control sisters (as-grown) and P-gettered samples.

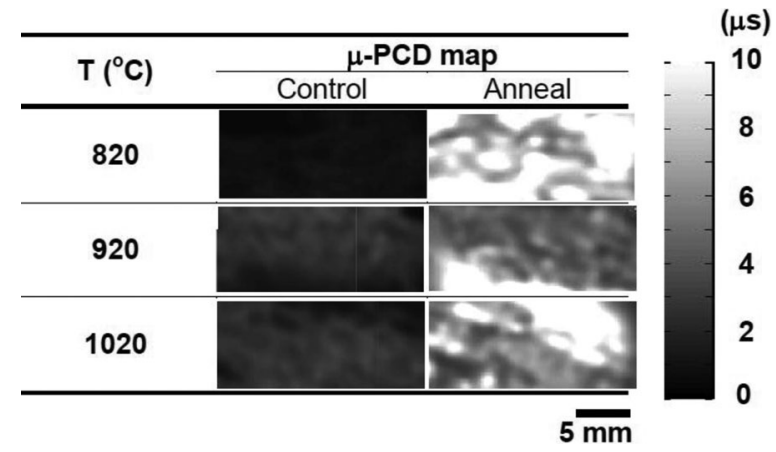

Fig. 4. Minority carrier lifetime maps of control sister (as-grown) and P-gettered samples from set A, which were measured by $\mu$-PCD.

of $\mathrm{Cu}$ atoms have successfully diffused from the $\mathrm{Cu}$ film to the gettering layer during both $\mathrm{Al}$ and $\mathrm{P}$ gettering, evidencing a net unidirectional flux of impurities through the sample. Negligible (below the detection limit of the spectrometer, $\sim 0.1 \mathrm{ppmw}$ ) $\mathrm{Cu}$ accumulation was observed in the gettering layers of samples without an external $\mathrm{Cu}$ film. The Al-gettered sample shows a slightly larger $\mathrm{Cu}$ peak than the P-gettered sample. Since both samples were taken from the same height from the same ingot and the evaporation was conducted at the same time, it is assumed that they have approximately the same amount of initial $\mathrm{Cu}$ contamination and the same thickness of the external $\mathrm{Cu}$ film. Hence, Al gettering is considered to be slightly more effective than $\mathrm{P}$ gettering under this annealing condition. This result is consistent with previous reports indicating improved gettering kinetics for an $\mathrm{Al}$ gettering layer, which forms more rapidly compared with P-diffused layer [33]. Relatively limited gettering efficiency could also be due to a reduced "capacity" (i.e., thickness-solubility product) of the P-gettered layer compared with the Al-Si layer [34].
Fig. 7 shows flatbed scanner images of dislocation-etched samples from set B. Optical microscope dislocation etch pit images of the representative areas marked by the black rectangles in Fig. 7 are shown in Fig. 8. The density and distribution of dislocations are similar after gettering at $820^{\circ} \mathrm{C}$ for samples without a $\mathrm{Cu}$ film. In the samples with the external $\mathrm{Cu}$ film, however, most dislocations are removed after gettering - a result similar to the observation for samples from set A. The sample with a 5-nm-thick external $\mathrm{Cu}$ film shows more than a $60 \%$ dislocation density reduction after $\mathrm{P}$ gettering and an $\sim 50 \%$ of dislocation density reduction after $\mathrm{Al}$ gettering.

\section{DISCUSSION}

\section{A. Effect of Dislocation-Impurity Interactions on Dislocation Density Reduction}

Two possible mechanisms for dislocation density reduction in crystalline materials are 1) in-grain pairwise annihilation by dislocation dipole interaction and 2) annihilation at grain boundaries or surface sinks [35]. Our analysis begins with consideration of a sole effect of the first, that is, dislocation pairwise annihilation. Here, the main driving force for dislocation annihilation is an internal force between dislocations of opposite sign, and the evolution in dislocation density as a function of annealing temperature $T$ and time $t$ can be expressed as [36]

$$
\sqrt{\frac{N}{N_{0}}} \cong\left[1+\frac{t}{A \exp (B / k T)}\right]^{-1}
$$

where $N_{0}$ and $N$ are the initial dislocation density and the dislocation density after annealing, respectively. $A$ and $B$ are constants-detailed information on these constants in (2) is given in [36].

According to (2), the dislocation density evolution $\left(N / N_{0}\right)$ is calculated to be $0.9999,0.9994$, and 0.9952 after annealing at 


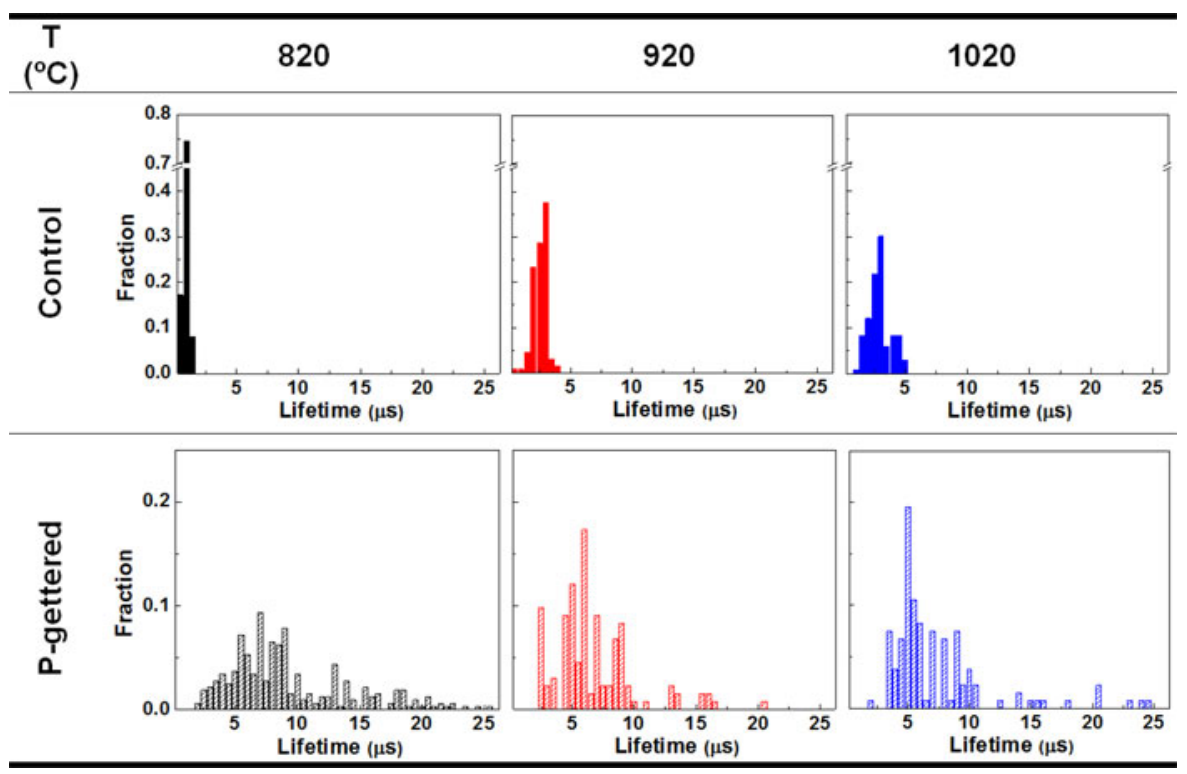

Fig. 5. Histograms of the minority carrier lifetime distribution throughout the samples from set A, where the counting was conducted for every 1-mm ${ }^{2}$ section of the control sisters (as-grown) and P-gettered samples.

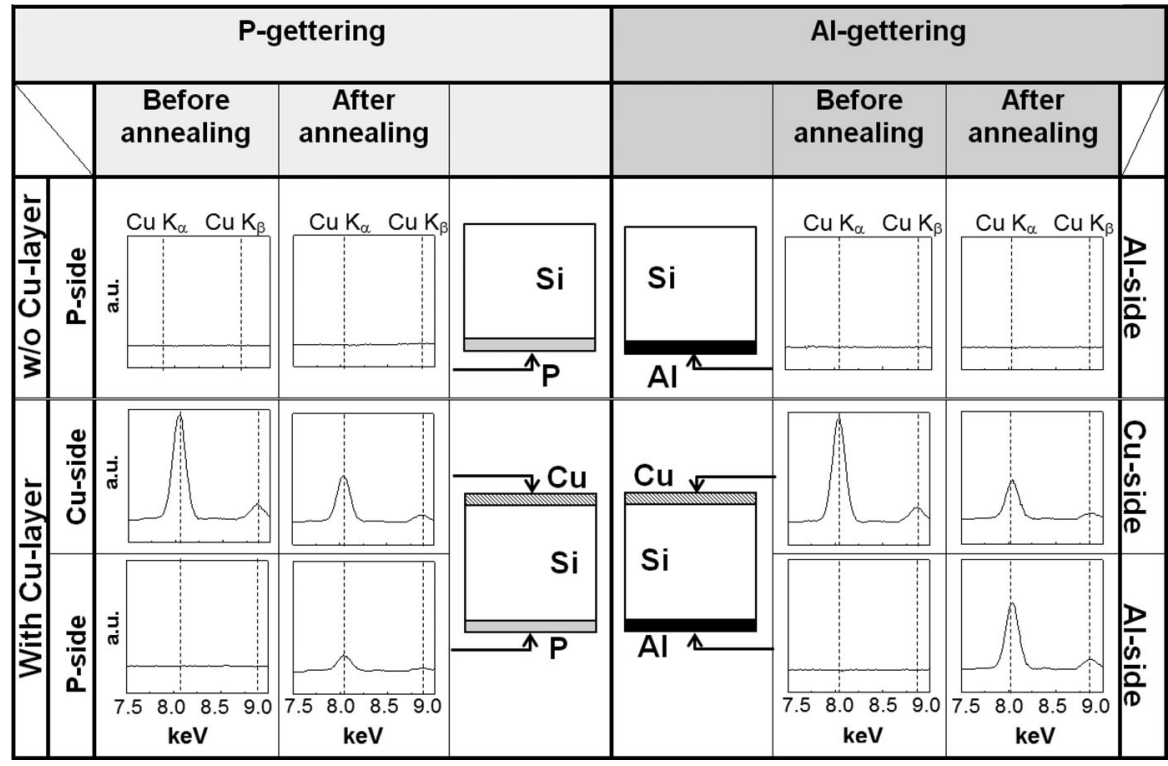

Fig. 6. XRF spectra of samples, which are grouped into two different surface treatments (with and without the contaminating copper film) and two different gettering methods (P gettering and Al gettering). Annealing conditions are described in Table I.

820,920 , and $1020^{\circ} \mathrm{C}$ for $2 \mathrm{~h}$, respectively-i.e., virtually no dislocation density reduction should be observed. This calculation is well matched with the measurements in the present study for samples from set $\mathrm{A}$ annealed without a $\mathrm{P}$ layer, that is, $1.03 \pm 0.07,1.08 \pm 0.09$, and $0.97 \pm 0.08$ after annealing at 820,920 , and $1020^{\circ} \mathrm{C}$ for $2 \mathrm{~h}$, respectively. Annealing at such low temperatures has been reported to have negligible effect on dislocation annihilation [16]-[19]. Moreover, at temperatures below $1000^{\circ} \mathrm{C}$, it has been known that dislocations cannot move freely because limited vacancy migration inhibits dislocation climb [37], [38], limiting dislocation pairwise annihilation.

Within this framework, our observation of significant dislocation density reduction after annealing at $820^{\circ} \mathrm{C}$ is unex- pected. The simultaneous presence of a gettering layer and an impurity source seems to be the key to explain these effects. Our results suggest that this combination significantly stimulates dislocation movement, even at lower temperatures. Recall that samples with moderate contamination levels (set A) showed significant dislocation density reduction after gettering, as shown in Fig. 2, while samples with low-impurity contents and without intentional contamination (set B) presented much less dislocation density change after the same external gettering time-temperature profile as shown in Fig. 8. Although set A has P-diffused layers on both sides, while set B has a gettering layer on one side, the dislocation-density evolution was observed nearby (1 $\mathrm{mm}$ away from) the gettering layer for both 


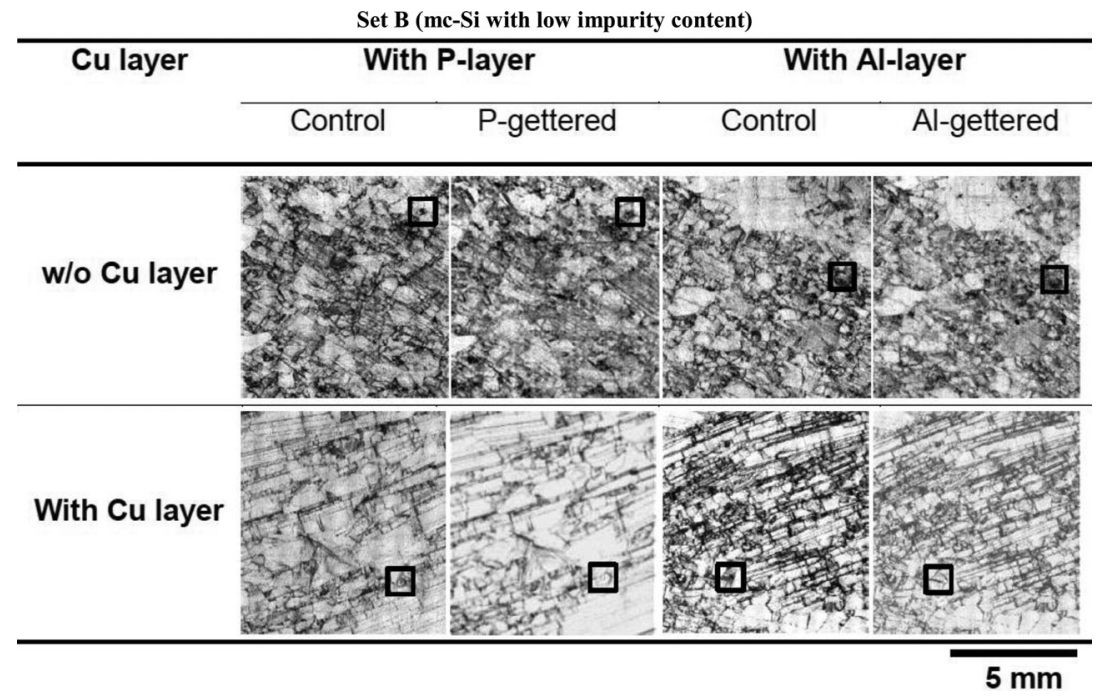

Fig. 7. Flatbed scanner images of dislocation-etched samples from set B; control sister (as-grown) and annealed samples, grouped into two different contamination levels (with and without a 5-nm-thick $\mathrm{Cu}$ film) and two different surface treatments (with an Al layer and with a P layer). High-resolution optical microscope images of representative black squares are shown in Fig. 8, and annealing conditions are described in Table I.

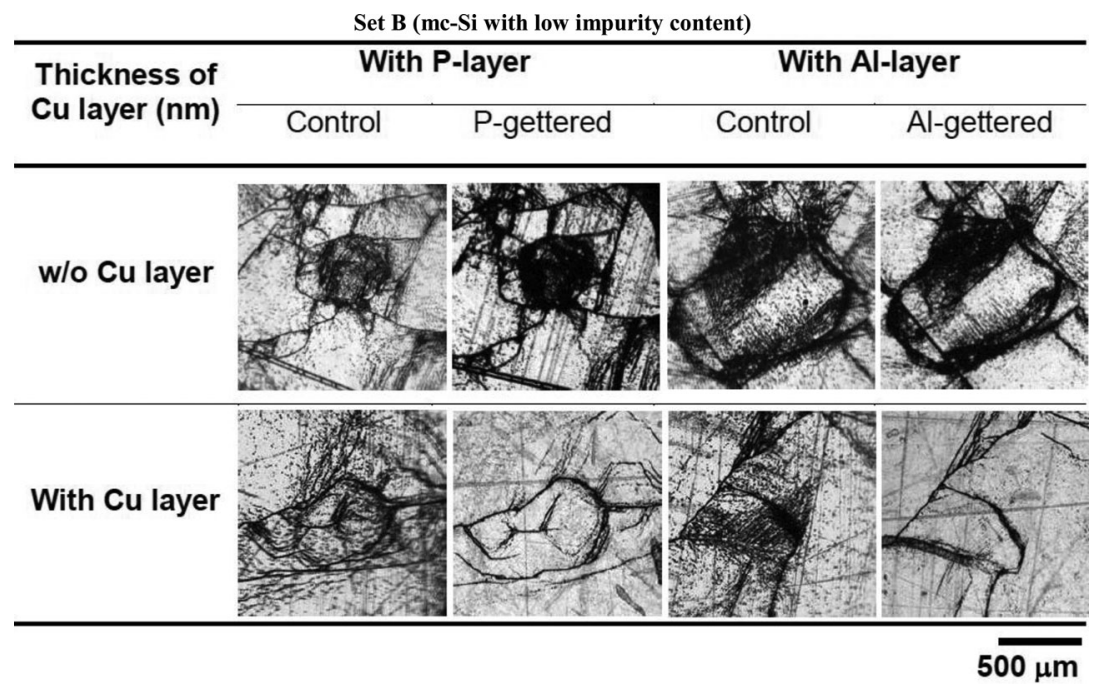

Fig. 8. Optical microscope dislocation etch pit images of control sister (as-grown) and annealed samples from set B, grouped into two different contamination levels (with and without a 5-nm-thick $\mathrm{Cu}$ film) and two different surface treatments (with an $\mathrm{Al}$ layer and with a P layer). Annealing conditions are described in Table I.

sets A and B. Furthermore, samples with low-impurity contents (set B) exhibited a dislocation density reduction after gettering annealing with an external $\mathrm{Cu}$ contamination source, as shown in Fig. 8. Based on this observation, we postulate that an additional driving force for dislocation motion arises from the presence of a net unidirectional flux of metal impurity atoms through the sample thickness. The solubility of metal impurities is much higher in the gettering layer than in the p-type silicon bulk, resulting in a net flux of impurity atoms toward the gettering layers [39].

Usually, the presence of impurities is associated with dislocation drag and mobility reduction. Certain impurities can cause a fractional change of the elastic modulus and a lattice distortion around dislocations, thereby attracting dislocations to lower the strain energy of the system [40]. If the motion of impurities is random, it stands to reason that this attractive force can reduce dislocation mobility. However, the same attractive force between dislocations and impurities may enable a unidirectional flux of impurities to drive dislocations to sink sources. Fig. 9 schematically describes a net force on a bulk dislocation, varied according to the presence of a P-diffused layer.

This hypothesis is supported by the two experiments presented earlier. In the first experiment, the dislocation density reduction is observed to be most significant $\mathrm{P}$ gettering at $820^{\circ} \mathrm{C}$. The effective solubility of certain transition metal impurities (including $\mathrm{Cu}$ ) in the P-diffused layer is several orders of magnitude higher than their solubility in the p-type silicon bulk. During $\mathrm{P}$ diffusion, this difference in solubility results in a driving force for impurity point defects to diffuse toward the P-diffused sink layer, gettering metal impurities. However, the segregation coefficient, which is the ratio of solubility in the gettering layer to the bulk, generally decreases as the temperature increases. The 


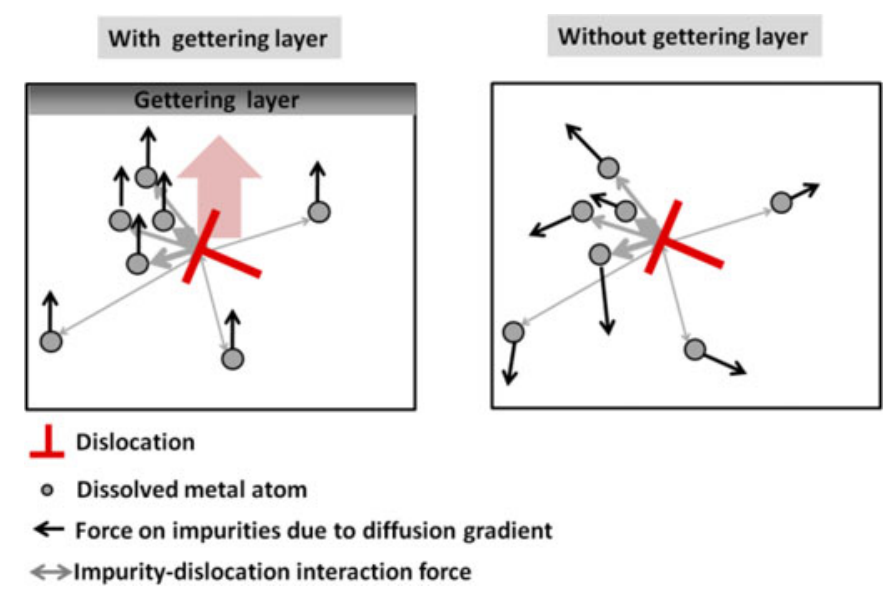

Fig. 9. Simplified schematic of the hypothesized phenomenon, whereby a net impurity flux (in the presence of a gettering layer) exerts a net force on bulk dislocations, driving dislocations to nearby sinks and resulting in net dislocation density reduction. The thickness of the arrows represents the approximate/relative magnitudes of different forces.

corresponding driving force for impurity gettering is thus reduced at higher temperatures. Consequently, the force with which a unidirectional flux of impurity point defects are hypothesized to exercise on dislocations is also reduced, which is consistent with the observation that dislocation density reduction is less significant at higher temperatures.

During a $\mathrm{P}$ gettering process, $\mathrm{P}$ atoms diffuse into the bulk, generating intrinsic point defects. One can expect that the excess point defects generated during $\mathrm{P}$ in-diffusion might lead to dislocation climb, followed by overall dislocation density reduction [41], [42]. However, several arguments speak against this hypothesis: First, it was observed in the second experiment that gettering alone is insufficient to result in dislocation density reduction in samples with low impurity content (see set B in Fig. 8). This is consistent with the previous reports on the negligible change of dislocation density during a conventional $P$ diffusion in high-purity silicon [43], which has much lower amount of impurities than silicon used for the first experiment (see set A in Fig. 2). When a source of impurities in the form of a $\mathrm{Cu}$ film is on one side of silicon from set $\mathrm{B}$, however, we observe a significant dislocation reduction on the order of 55 and $60 \%$ during $\mathrm{Al}$ and $\mathrm{P}$ gettering, respectively. The net unidirectional flux of $\mathrm{Cu}$ atoms from a $\mathrm{Cu}$ film to a gettering layer may drive dislocations to sink sites, leading to an overall dislocation density reduction. Second, the effect of excessive vacancies or silicon self-interstitials has been reported to diminish as the distance from the P-diffused layer increases, and hence, these effects are thought to be negligible in the observed regions that are $\sim 1 \mathrm{~mm}$ apart from the original surface [44]-[46]. Third, the dislocation density reduction we observe becomes less significant with increasing gettering temperature despite what should be a higher excess vacancy concentration at higher temperatures. Fourth, in the second experiment, Al gettering, which is expected to generate a different excess point defects concentration, is also found to be effective for dislocation density reduction for samples containing moderate concentrations of metal impurities. Consequently, the effect of excess point de- fects during P gettering may be insufficient to cause dislocation density reduction in such a thick slab of silicon. Further studies to quantify the effect of concentration and flux of impurity atoms on dislocation motion during various gettering processes may be conducted in the future.

\section{B. Decoupling the Effects of Dislocation-Density Reduction and Impurity Gettering on Lifetime Improvement}

Minority carrier lifetime as a function of dislocation density is plotted in Fig. 10 for sample set A. Here, each data point represents the average dislocation density and lifetime of a $1 \times 1 \mathrm{~mm}^{2}$ area of the sample. In most regions of the as-grown control samples, the minority carrier lifetime is constant, independent of the dislocation density, presenting a plateau-type curve. Presumably, this is because impurity concentrations in the as-grown control samples are so high that the lifetime is not limited by dislocations but by metal impurities. In regions with dislocation densities ranging from $10^{7}$ to $10^{8} \mathrm{~cm}^{-2}$, however, the lifetime decreases with an increase in dislocation density, indicating a lifetime limitation from dislocations as well. During P gettering, dissolved metal impurities diffuse toward and segregate into the $\mathrm{P}$ layer so that the overall impurity concentration in the bulk is reduced [47]. After gettering, the minority carrier lifetime shows a strong dependence on the dislocation density even for dislocation densities below $10^{6} \mathrm{~cm}^{-2}$, indicating the lifetime for higher purity samples is more sensitive to dislocation density.

The effective minority carrier lifetime $\tau_{e}$ can be expressed as a function of dislocation-limited lifetime $\tau_{d}$ and the lifetime in the dislocation-free semiconductor $\tau_{0}$, per Donolato's model [25]

$$
\frac{1}{\tau_{e}}=\frac{1}{\tau_{d}}+\frac{1}{\tau_{0}}
$$

According to this model [25], the relation between dislocation-limited lifetime and dislocation density $\rho_{d}$ can be expressed as follows:

$\tau_{d} \cong \frac{1}{2 \pi \rho_{d} D}\left[-\ln \left(\varepsilon \rho_{d}^{1 / 2}\right)-\frac{\ln (\pi)}{2}-C+\frac{1}{2}\right]+\frac{1}{2 \pi \varepsilon v_{s} \rho_{d}}$.

Here, $D$ is the diffusivity of the electrons in perfect silicon ( $\left.\sim 33.5 \mathrm{~cm}^{2} / \mathrm{s}\right), \varepsilon$ is the dislocation radius $(0.75 \mu \mathrm{m}), C$ is the Euler's constant, and $v_{s}$ is the dislocation-surface recombination velocity. In this model, a dislocation is represented by a cylinder with given $v_{s}$. Based on (3) and (4), nonlinear fitting was conducted to find values for $\tau_{0}$ and $v_{s}$. From $v_{s}$, the line recombination velocity $\gamma_{d}$ at dislocations is calculated as in [25]

$$
\gamma_{d}=2 \pi \varepsilon v_{s}
$$

Fitted values of $\tau_{0}$ and $\gamma_{d}$ are given in Fig. 10. Values of the electron lifetime for the dislocation-free semiconductor $\tau_{0}$ are estimated to be $\sim 21.9, \sim 11.9$, and $\sim 13.3 \mu$ s after P gettering at 820,920 , and $1020^{\circ} \mathrm{C}$, while those for their sister control samples are $\sim 1.0, \sim 2.6$, and $\sim 3.5 \mu$ s, respectively. A comparison shows that the effect of impurity concentration reduction during $\mathrm{P}$ gettering on lifetime is found to be significant: The background lifetime is enhanced by more than 20 times after $P$ 

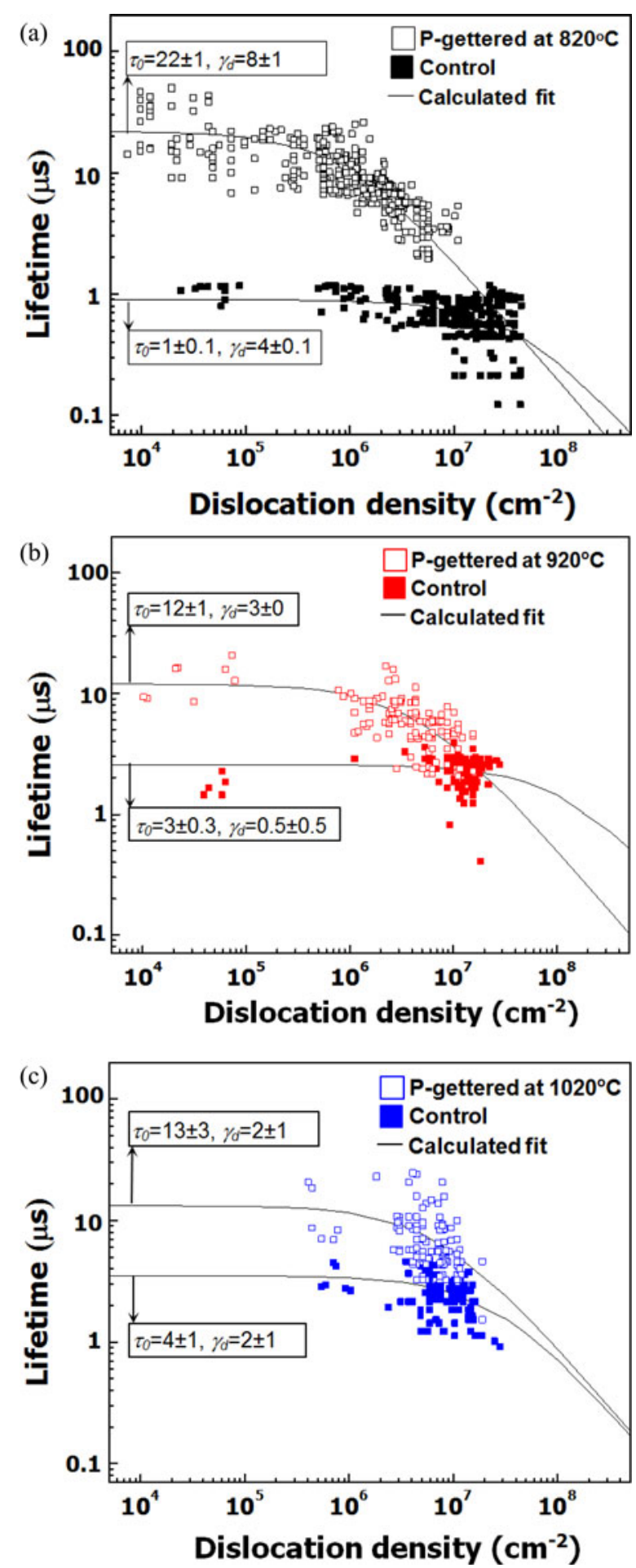

Fig. 10. Minority carrier lifetime as a function of dislocation density for sample set A, as-grown (Control, solid squares) and as P-gettered (Anneal, open squares) at (a) 820 (black-colored), (b) 920 (red-colored), and (c) $1020^{\circ} \mathrm{C}$ (blue-colored). Units for $\tau_{0}$ and $\gamma_{0}$ are $\mu \mathrm{s}$ and $\mathrm{mm}^{2} / \mathrm{s}$, respectively.

gettering at $820^{\circ} \mathrm{C}$, about five times at $920^{\circ} \mathrm{C}$, and about four times at $1020^{\circ} \mathrm{C}$.

By applying (3), the average dislocation-limited lifetime $\tau_{d}$ is calculated from the effective measured lifetimes $\tau_{e}$ and the fitted background lifetimes $\tau_{0}$. The values are found to be $\sim 42.9$, $\sim 15.3$, and $\sim 12.3 \mu$ s for samples after $\mathrm{P}$ gettering at 820,920 , and $1020^{\circ} \mathrm{C}$ and $\sim 4.2, \sim 4.0$, and $\sim 4.0 \mu$ s for their sister control samples, respectively. This means that the dislocation-limited lifetime is also enhanced by about ten times after $\mathrm{P}$ gettering at $820^{\circ} \mathrm{C}$, and it is enhanced by about three to four times after $\mathrm{P}$ gettering at 920 and $1020^{\circ} \mathrm{C}$, respectively. This suggests that dislocation density reduction during $\mathrm{P}$ gettering also plays a significant role in increasing minority carrier lifetime.

Interestingly, values for the recombination strength of dislocations $\gamma_{d}$ are found to be higher after gettering. In turn, dislocations seem to be more recombination-active after $\mathrm{P}$ gettering. A possible explanation is that dislocations which are initially clean (i.e., not decorated with homogeneously distributed impurities) and, thus, less recombination-active might become contaminated by impurities during $\mathrm{P}$ gettering. However, the fitting error, especially for as-grown samples, is comparably large, and the data toward high dislocation densities is influenced by the detection limit inherent to the dislocation counting method. Further investigation of the interplay between dislocations and metal impurities during $\mathrm{P}$ diffusion gettering and their combined effect on minority carrier lifetimes is required.

Despite these encouraging results, much is still to be understood regarding this "impurity-induced dislocation-density reduction" effect reported herein. For instance, when a 10-nmthick $\mathrm{Cu}$ layer (as opposed to the 5-nm-thick layer reported herein) is deposited on the back of samples prepared similarly to Set B, a much smaller dislocation density reduction is observed, suggesting that an impurity amount that is too high can be detrimental. Furthermore, dislocation-density reduction during phosphorus diffusion is not commonplace. Thus, it is our opinion that only by understanding the underlying thermodynamics and kinetics of the phenomena reported herein may we eventually develop a robust, controllable, and industrial process.

\section{CONCLUSION}

Dislocation density reductions of $\sim 60 \%$ are observed in solargrade mc-Si with moderate impurity concentration levels after $\mathrm{P}$ gettering at $820^{\circ} \mathrm{C}$. XRF confirms the diffusion of impurities toward the gettering layer. It is hypothesized that this net unidirectional impurity flux may drive dislocations to sink sites, leading to an overall dislocation density reduction. This hypothesis is supported by two experiments. First, we observe a decreased magnitude of dislocation density reduction with increasing gettering temperature, possibly because of a weaker driving force for impurity segregation gettering at higher annealing temperatures. Second, we do not observe dislocation density reduction after gettering in high-purity mc-Si, except when an external metal source from a $\mathrm{Cu}$ film is present during annealing. A Donolato-style analysis reveals that the minority carrier lifetime improvement after $\mathrm{P}$ gettering of solar-grade mc-Si with moderate impurity concentrations is attributable to a reduction of both impurity concentration and dislocation density.

\section{ACKNOWLEDGMENT}

The authors would like to thank S. Hudelson (1366 Technologies) for Secco etching support and Prof. D. M. Parks (MIT) and 
Prof. D. Trinkle (UIUC) for helpful discussions. They would also like to thank the Center for Nanoscale Systems (CNS) at Harvard University, which is a member of the National Nanotechnology Infrastructure Network.

\section{REFERENCES}

[1] P. Mints, presented at the SunShot Silicon PV Roundtable Discussion, DoE, May 3, 2012.

[2] B. L. Sopori and W. Chen, "Influence of distributed defects on the photoelectric characteristics of a large-area device," J. Cryst. Growth, vol. 210, no. $1-3$, pp. 375-378, 2000.

[3] A. Goetzberger and C. Hebling, "Photovoltaic materials, past, present, future," Sol. Energy Mater. Sol. Cells, vol. 62, no. 1-2, pp. 1-19, 2000.

[4] B. Sopori, "Silicon solar-cell processing for minimizing the influence of impurities and defects," J. Electron. Mater, vol. 31, no. 10, pp. 972-980, 2002.

[5] J. S. Kang and D. K. Schroder, "Gettering in silicon," J. Appl. Phys., vol. 65 , no. 8, pp. 342714-342725, 1989.

[6] M. Loghmarti, R. Stuck, J. C. Muller, D. Sayah, and P. Siffert, "Strong improvement of diffusion length by $\mathrm{P}$ and Al gettering," Appl. Phys. Lett., vol. 62, no. 9, pp. 108539-108541, 1993.

[7] H. El Ghitani and S. Martinuzzi, "Modelling of recombination activity and passivation by hydrogen of dislocations in silicon wafers," Mater. Sci. Eng. B, vol. 4, no. 1-4, pp. 153-156, 1989.

[8] G. G. DeLeo, G. D. Watkins, and W. B. Powler, "Theory of interstitial transition-metal impurities in silicon," Phys. Rev. B, vol. 23, no. 4, pp. $1851-1858,1981$.

[9] E. R. Weber, "Transition metals in silicon," Appl. Phys. A: Mater. Sci. Process, vol. 30, no. 1, pp. 1-22, 1983.

[10] A. Bentzen, A. Holt, R. Kopecek, G. Stokkan, J. S. Christensen, and B. G. Svensson, "Gettering of transition metal impurities during P emitter diffusion in multicrystalline silicon solar cell processing," J. Appl. Phys., vol. 99, no. 9, pp. 093509-093513, 2006.

[11] H. Wang, H. Yang, H. Yu, and G. Chen, "Influence of gettering and passivation on uniformity of the electrical parameters in monolithic multicrystalline silicon solar cell," Solid State Electron., vol. 47, no. 8, pp. 1363 1367,2003

[12] S. A. McHugo, H. Hieslmair, and E.R. Weber, "Gettering of metallic impurities in photovoltaic silicon," Appl. Phys. A: Mater. Sci. Process., vol. 64, no. 2, pp. 127-137, 1997.

[13] S. A. McHugo and W. D. Sawyer, "Impurity decoration of defects in float zone and polycrystalline silicon via chemomechanical polishing," Appl. Phys. Lett., vol. 62, no. 20, pp. 2519-2521, 1993.

[14] P. R. Wilshaw, T. S. Fell, and M. D. Coteau, "EBIC contrast of defects in semiconductors," J. Phys. IV France, vol. 1, no. C6, pp. 3-14, 1991.

[15] S. Binetti, S. Ratti, M. Acciarri, and S. Pizzini, "Study of different polycrystalline silicon materials: effect of hydrogen and deuterium passivation," in Proc. 12th Eur. Photovoltaics Sol. Energy Conf., 1994, p. 709.

[16] K. Hartman, M. Bertoni, J. Serdy, and T. Buonassisi, "Dislocation density reduction in multicrystalline silicon solar cell material by high temperature annealing," Appl. Phys. Lett., vol. 93, no. 12, pp. 122108-122110, 2008.

[17] M. Bertoni, C. Colin, and T. Buonassisi, "Dislocation engineering in multicrystalline silicon," Solid State Phenom., vol. 156-158, pp. 11-18, 2010.

[18] H.B. Xu, R. J. Hong, and H. Shen, "Effects of high temperature annealing on the dislocation density and electrical properties of upgraded metallurgical grade multicrystalline silicon," Chin. Sci. Bull., vol. 56, no. 7, pp. 695-699, 2011.

[19] G. Stokkan, C. Rosario, M. Berg, and O. Lohne, "High temperature annealing of dislocations in multicrystalline silicon for solar cells," in Solar Power, R. D. Rugescu, Ed. Hampshire, U.K.: InTech, 2012.

[20] D. Kuhlmann, "On the theory of plastic deformation," Proc. Phys. Soc. London A, vol. 64, no. 2, pp. 140-155, 1951.

[21] K. Sumino, "Dislocations and mechanical properties of silicon," Mater. Sci. Eng. B, vol. 4, no. 1-4, pp. 335-341, 1989.

[22] J. Samuels and S. G. Roberts, "The brittle-ductile transition in silicon. I. experiments," Proc. R. Soc. London, Ser. A, vol. 421, no. 1, pp. 1-23, 1989.

[23] S. Takeuchi and A. S. Argon, "Steady-state creep of single-phase crystalline matter at high temperature," J. Mater. Sci., vol. 11, no. 8, pp. 15421566, 1976.

[24] D. Franke, "Change of dislocation density in silicon wafers during thermal processing," in Proc. 28th IEEE Photovoltaic Spec. Conf., 2000, pp. 237240.
[25] C. Donolato, "Modeling the effect of dislocations on the minority carrier diffusion length of a semiconductor," J. Appl. Phys., vol. 84, no. 5, pp. 2656-2664, 1989.

[26] M. Krzywiecki, L. Grzdziela, H. Peisert, I. Biswas, T. Chassé, and J. Szuber, "X-ray photoelectron spectroscopy characterization of native and RCA-treated $\mathrm{Si}\left(\begin{array}{lll}1 & 1 & 1\end{array}\right)$ substrates and their influence on surface chemistry of $\mathrm{Cu}$ phthalocyanine thin films," Thin Solid Films, vol. 518, no. 10, pp. 2688-2694, 2010.

[27] M.D. Pickett and T. Buonassisi, "Iron point defect reduction in multicrystalline silicon solar cells," Appl. Phys. Lett., vol. 92, no. 12, pp. 122103122105, 2008.

[28] M. Rinio, A. Yodyunyong, S. Keipert-Colberg, Y.B. Mouafi, D. Borchert, and A. Montesdeoca-Santana, "Improvement of multicrystalline silicon solar cells by a low temperature anneal after emitter diffusion," Prog. Photovolt., vol. 92, no. 2, pp. 165-169, 2011.

[29] B. L. Sopori, "Use of optical scattering to characterize dislocations in semiconductors," Appl. Opt., vol. 27, no. 22, pp. 4676-4683, 1988.

[30] D. Bouhafs, M. Fathi, and L. Guerbous, "Photoluminescence activity of Yang and Secco etched multicrystalline silicon material," Appl. Surf. Sci., vol. 252, no. 23, pp. 8337-8340, 2006.

[31] M. Rinio, "Untersuchung der prozessabhängigen Ladungsträgerrekombination an Versetzungen in Siliziumsolarzellen," Ph.D. dissertation, Inst. Experimental Phys., Tech. Univ. Bergakademie, Freiberg, Germany, 2004.

[32] R. Bakowskie, H. von Wenckstern, D. Lausch, M. Mueller, K. Petter, and M. Grundmann, "Thermal admittance spectroscopy of multicrystalline silicon wafers and solar cells," in Proc. 24th Eur. Photovoltaic Sol. Energy Conf., 2009, pp. 2100-2102.

[33] M. A. Falkenberg, D. Abdelbarey, V. V. Kveder, and M. Seibt, "Comparison of efficiency and kinetics of P-diffusion and Al gettering of metal impurities in silicon: A simulation study," Solid State Phenom., vol. 156158, pp. 229-234, 2009.

[34] W. Schröter and M. Seibt, in Properties of Crystalline Silicon, R. Hull, Ed. London, U.K.: INSPEC, 1999.

[35] L. Wang, Z. Zhang, E. Ma, and X. D. Han, "Transmission electron microscopy observations of dislocation annihilation and storage in nanograins," Appl. Phys. Lett., vol. 98, no. 5, pp. 051905-051907, 2011.

[36] E. Nes, "Recovery revisited," Acta metall. mater, vol. 43, no. 6, pp. 2189 2207, 1995 .

[37] A. S. Argon, Strengthening Mechanisms in Crystal Plasticity. New York: Oxford Univ. Press, 2008.

[38] S. Takeuchi and A. S. Argon, "Steady-state creep of single-phase crystalline matter at high temperature," J. Mater. Sci., vol. 11, no. 8, pp. 1542 1566, 1975.

[39] H. M. You, U. Gösele, and T. Y. Tan, "Simulation of the transient indiffusion-segregation process of triply negatively charged Ga vacancies in GaAs and AlAs/GaAs superlattices," J. Appl. Phys., vol. 72, no. 4, pp. 2461-2470, 1993.

[40] T. M. Courtney, Mechanical Behavior of Materials, 2nd ed. New York: McGraw-Hill, 2000, p. 186.

[41] F. N. Schwettmann and D. L. Kendall, "On the nature of the kink in the carrier profile for P-diffused layers in silicon," Appl. Phys. Lett., vol. 21, no. 1, pp. $2-4,1972$.

[42] E. Kasper, K. Lyutovich, M. Bauer, and M. Oehme, "New virtual substrate concept for vertical MOS transistors," Thin Solid Films, vol. 336, no. 1-2, pp. 319-322, 1998.

[43] K. Lauer, M. Herms, A. Grochocki, and J. Bollmann, "Iron gettering at slip dislocations in czochralski silicon," Solid State Phenom., vol. 178-179, pp. 211-216, 2011.

[44] M. Yoshida, "Excess vacancy generation mechanism at P diffusion into silicon," J. Appl. Phys., vol. 45, no. 4, pp. 1498-1506, 1974.

[45] A. Ural, P. B. Griffin, and J. D. Plummer, "Self-diffusion in silicon: similarity between the properties of native point defects," Phys. Rev. Lett., vol. 83, no. 17, pp. 3454-3457, 1999.

[46] M. Seibt, A. Sattler, C. Rudolf, O. Voß, V. Kveder, and W. Schröter, "Gettering in silicon photovoltaics: current state and future perspectives," Phys. Stat. Sol. (A), vol. 203, no. 4, pp. 696-713, 2006.

[47] D. M. Powell, D. P. Fenning, J. Hofstetter, J. F. Lelièvre, C. D. Cañizo, and T. Buonassisi, "TCAD for PV: A fast method for accurately modelling metal impurity evolution during solar cell process," Photovoltaics Int., vol. 15, pp. 91-100, 2012.

Authors' photographs and biographies not available at the time of publication. 